\title{
Malignant rhabdoid tumour in an adult kidney: A case report
}

\author{
YOSHINAGA OKUMURA ${ }^{1}$, YASUSHI ADACHI ${ }^{2}$, TOSHIHIRO SHIRAHASE ${ }^{1}$, YOJI NAGASHIMA ${ }^{3}$, \\ YUKICHI TANAKA $^{4}$, YOJI TAKI $^{1}$, JUN WATANABE $^{1}$, MASAYUKI UEGAKI $^{1}$, \\ TORU SAKATANI ${ }^{1}$ and SUSUMU IKEHARA ${ }^{5}$ \\ Departments of ${ }^{1}$ Urology and ${ }^{2}$ Diagnostic Pathology, Toyooka Hospital, Toyooka, Hyogo 668-8501; \\ ${ }^{3}$ Department of Surgical Pathology, Tokyo Women's Medical University, Tokyo 162-8666; \\ ${ }^{4}$ Clinical Research Institute and Department of Pathology, Kanagawa Children's Medical Center, Yokohama, \\ Kanagawa 232-8555; ${ }^{5}$ Professor Emeritus, Kansai Medical University, Hirakata, Osaka 573-1010, Japan
}

Received July 18, 2018; Accepted March 20, 2019

DOI: $10.3892 /$ mco.2019.1848

\begin{abstract}
Malignant rhabdoid tumours (MRTs) in the kidney are rare paediatric tumours that are extremely rare in adults. We herein report the case of an adult patient with a renal MRT. A 79-year-old Japanese woman was found to have a tumour sized $63 \times 48 \mathrm{~mm}$ in the left kidney, in addition to multiple metastatic bone and lymph node lesions. The needle biopsy specimen obtained from the patient's kidney revealed tumour cells with rhabdoid characteristics: The cells appeared large, round or polygonal, with eccentrically located nuclei and prominent nucleoli. Immunohistochemically, the tumour cells were positive for vimentin, epithelial membrane antigen, CAM 5.2, and p53, and negative for INI1, cytokeratin (CK)7, CK20, $\alpha$-methylacyl-CoA racemase, S100, CD45, renal cell carcinoma marker, anaplastic lymphoma kinase, $\alpha$-smooth muscle actin, desmin, MyoD, myogenin, human melanoma black 45 and melan A. Therefore, the tumour was diagnosed as an MRT located in the kidney. Although the patient was treated with axitinib, a tyrosine kinase inhibitor, the renal tumour and its metastatic lesions continued to progress, and the number of metastatic lesions increased. The patient succumbed to the disease 5 months after the first hospital visit. The disease progression was rapid, with a poor prognosis, consistently with previous reports that of MRTs in the adult kidney.
\end{abstract}

\section{Introduction}

Malignant rhabdoid tumours (MRTs) of the kidney are rare tumours that occur mainly in children (1). Cases of

Correspondence to: Dr Yasushi Adachi, Department of Diagnostic Pathology, Toyooka Hospital, 1094 Tobera, Toyooka, Hyogo 668-8501, Japan

E-mail: adachiya250@gmail.com

Key words: malignant rhabdoid tumour, adult, kidney, biopsy, axitinib adult patients with renal MRT are extremely rare, with $<20$ such cases reported in the literature to date $(2-5)$. The hSNF/INI1/SMARCB1/BAF47 gene is hypothesized to act as a suppressor gene, and INI1 is expressed in normal cells throughout the body (6). Loss and inactivation of INI1 expression are associated with the development of MRT, atypical teratoid or rhabdoid tumour of the central nervous system in children, epithelioid sarcoma, collecting duct carcinoma, and epithelioid malignant peripheral nerve sheath tumour (7-11). We herein present a case of an adult patient with MRT of the left kidney with associated loss of INI1 expression and multiple metastatic lesions in the bones and lymph nodes.

\section{Case report}

A 79-year-old Japanese woman was admitted to Toyooka Hospital (Toyooka, Japan) on the 1st December 2016, complaining of pain in the right buttock and difficulty in ambulation. A computed tomography (CT) scan revealed a thoracic and lumbar spine deformity, narrowing of the spinal canal, and a tumour in the left kidney. The patient's medical history included a cerebral infarction at the age of 64 years, with no associated family history. Laboratory tests were performed at the time of the hospital visit and the results were as follows: C-reactive protein and KL-6 increase to $12.0 \mathrm{mg} / \mathrm{dl}$ (normal, $<0.3 \mathrm{mg} / \mathrm{dl}$ ) and $558 \mathrm{U} / \mathrm{ml}$ (normal, $<500 \mathrm{U} / \mathrm{ml}$ ), respectively; the urinary cytology was positive, suggesting malignancy.

An abdominal CT scan revealed a tumour sized $63 \times 48 \mathrm{~mm}$ extending towards the upper pole of the left kidney (Fig. 1). Invasion of the tumour into the renal pelvis was noted. The CT scan also revealed enlargement of the renal hilar and para-aortic lymph nodes. Bone scintigraphy demonstrated multiple bone metastatic lesions in the thoracic and lumbar spine, the skull and the pelvic bones (Fig. 2). These bone metastases were considered to be the cause of the pain in the buttock and difficulty in ambulation.

Percutaneous needle biopsy of the renal tumour was performed under echocardiographic guidance, followed by histological examination. Three samples were obtained, all 
of which contained atypical large tumour cells, with a small area of normal renal tissue (Fig. 3A and B). The tumour cells were large with round to polygonal shape, with eccentrically positioned nuclei and prominent nucleoli. The cytoplasm of the tumour cells was abundant and eosinophilic, resembling the so-called 'rhabdoid features' (12). No other histological tumour types were identified. Immunohistochemically, the tumour cells were positive for vimentin, epithelial membrane antigen, CAM 5.2 (Fig. 3C-E) and p53, and negative for cytokeratin (CK)7, CK20, $\alpha$-methylacyl-CoA racemase, S100, CD45, RCC-marker, anaplastic lymphoma kinase, $\alpha$-smooth muscle actin, desmin, MyoD1, myogenin, human melanoma black 45 and melan A (data not shown). The tumour cells were also negative for INI1, although lymphoid cells infiltrating among the tumour cells were positive for INI1 (Fig. 3F). A small part of the tumour was positive for CK(AE1/AE3) and CD10 (data not shown). Based on the microscopic morphology and the immunohistochemical examination, particularly the tumour cells staining negative for INI1, the tumour was diagnosed as a renal MRT.

Based on the clinical data, the tumour was stage cT1bN2M1 and had a score of 3 (poor risk group) in the Memorial Sloan-Kettering Cancer Centre (MSKCC) Motzer Score for metastatic RCC (13). Histological examination also suggested a poor prognosis. A tyrosine kinase inhibitor, axitinib, was administered. However, tumour growth continued, resulting in an enlargement of the original renal tumour and the metastatic lesions, and an increase in the number of metastatic lesions (Fig. 4). KL-6 also increased to $1,600 \mathrm{U} / \mathrm{ml} 3$ months after treatment initiation. The patient's general condition gradually worsened due to the growth of the original tumour, the metastatic lesions, and the side effects of the medication (including coughing and the elevation of sialylated carbohydrate antigen KL-6), resulting in treatment discontinuation (14). The patient succumbed to the disease 3.5 months after the treatment initiation.

\section{Discussion}

MRT development is associated with the loss of INI-1 expression (15-18). Biegel et al examined 18 patients with atypical teratoid rhabdoid tumours (ATRTs) of the brain, 7 patients with renal MRTs, and 4 patients with extrarenal rhabdoid tumours (17). All tumours harboured INI1 gene abnormalities, such as homozygous deletions or mutations of one or more exons. Germline mutations of the INI1 gene were identified in 4 of the 29 patients ( 3 of 7 patients with renal MRTs). Pinto et al reported that $\sim 80 \%$ of paediatric patients with multifocal synchronous or metachronous ATRTs and non-central nervous system MRTs exhibited heterozygous germline INI1 abnormalities (18). In experiments on mice, homozygous knockout of the INI1 gene resulted in embryonic lethality in utero. Although heterozygous knockout mice with the INI1 gene appear to be normal at birth, the mice develop tumours histologically similar to MRT in later life (6). These results suggest that INI1 is a tumour suppressor gene, and abnormalities of the INI1 gene are closely associated with the development of MRTs.
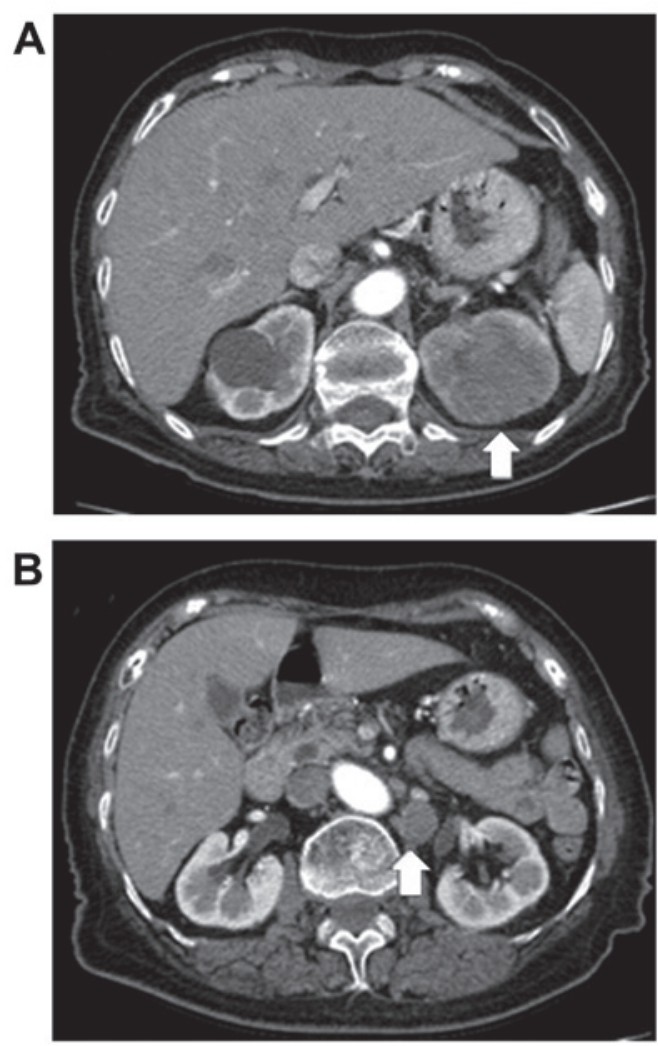

Figure 1. Contrast-enhanced computed tomography imaging on the patient's first visit to the hospital. (A) A tumour sized $63 \times 48 \mathrm{~mm}$ (arrow) was identified in the superior pole of the left kidney, invading the renal pelvis, and a retention cyst was observed in the right kidney. (B) Multiple enlarged lymph nodes, indicating lymph node involvement by the renal tumour. An enlarged left renal hilar lymph node measuring $20 \mathrm{~mm}$ in diameter (arrow) was also observed.

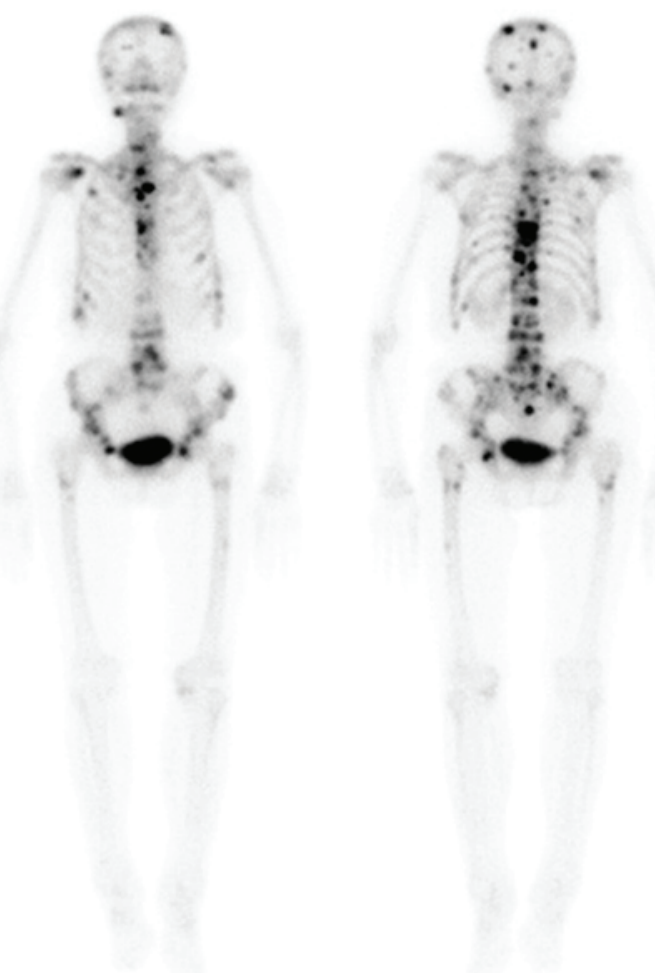

Figure 2. Bone scintigraphy images showing multiple metastatic lesions in the skull, thoracic spine, lumbar spine, pelvic bone and ribs. 
A

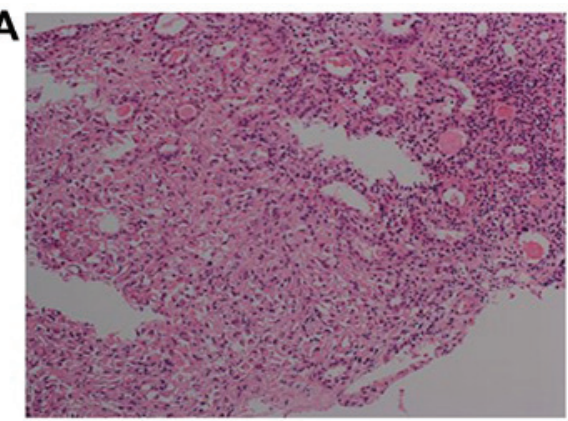

C

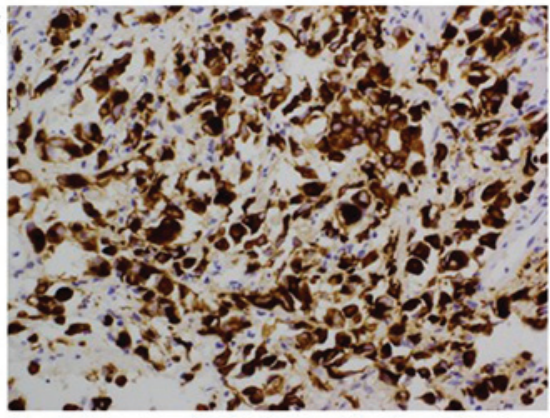

$\mathrm{E}$

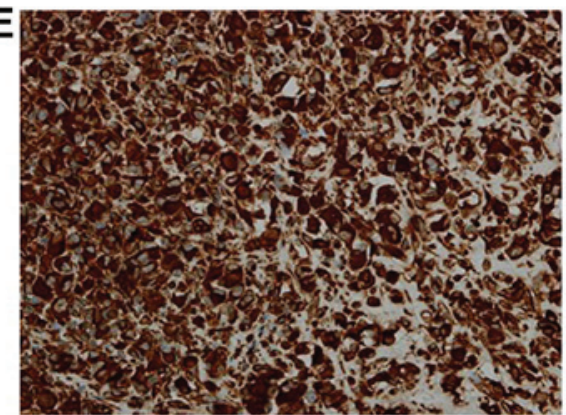

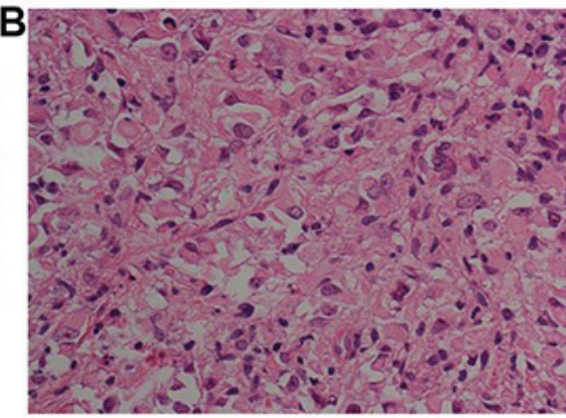
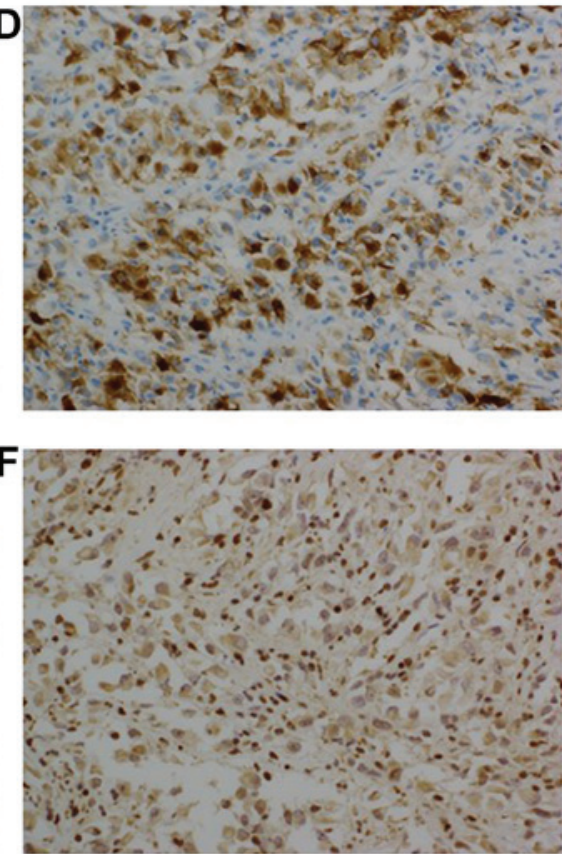

Figure 3. Histological examination of the haematoxylin and eosin-stained specimen at original magnifications of (A) x20 and (B) x60. Immunohistochemical staining for (C) CAM5.2, (D) epithelial membrane antigen, (E) vimentin and (F) INI1 (magnification, x40).
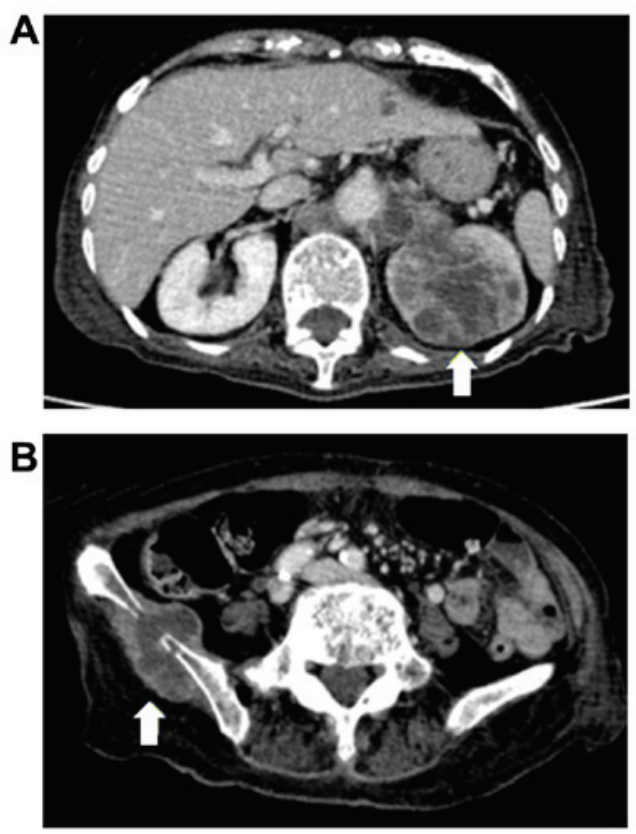

Figure 4. Contrast-enhanced computed tomography imaging 2 months after treatment initiation showing disease progression (arrows). (A) Enlargement of the original tumour and the metastatic lymph nodes. (B) New metastatic lesion of the iliac bone.
Although renal MRTs mainly occur in children, a few cases of adult MRTs have been reported. In addition, in the adult cases of MRT, loss of INI1 expression has also been reported in rare cases $(4,5)$. In the present case, we observed loss of INI1 expression in the tumour. It was also observed that the normal cells in the kidney of the patient expressed INI-1. Therefore, loss of INI1 was specific to the tumour cells. In the experiments on mice, the somatic cells of the heterozygous INI1-knockout mice expressed INI1, while the MRTs arising in mice exhibited loss of INI1 expression. Heterozygous abnormality of the INI1 gene has been reported in some children with MRTs (17). We were unable to undertake genomic analysis of the tumour in our patient; therefore, we were unable to determine whether the patient had a heterogenous abnormality in the INI1 gene or a normal INI1 gene within the somatic cells in her body. It has been reported that some adult MRT types coexist with other types of RCCs. In these cases, MRT is hypothesized to develop from RCC. However, to the best of our knowledge, only two adult MRTs with a confirmed loss of INI1 expression have been reported to date, and these were both pure MRTs. Our patient also displayed MRT histology alone, although only biopsy samples were obtained. From the experimental results in knockout mice, the INI1 gene appears to be a tumour-suppressor gene and 
has homogenous abnormalities, and deletion or mutation of the INI1 gene accelerates the development of MRT, without other gene abnormalities; however, the development of MRTs from other types of RCC requires multiple gene abnormalities. Therefore, it is recommended to examine INI1 expression in MRTs combined with other RCC types. Further studies should be conducted to elucidate the mechanism underlying the loss of INI1 expression and the development of MRT in adults.

Previous studies have reported that MRTs in adults are associated with a poor prognosis. Our patient succumbed to the disease 6 months after the symptoms first appeared, despite receiving treatment. Hence, medications that can suppress activated gene(s) through the loss of INI1 expression may prove to be of therapeutic value in adult MRT.

\section{Acknowledgements}

The authors would like to thank Ms H. Ogaki, Mr. K. Nagaoka, Mr. T. Kuge, and Mr. H. Takenaka of Toyooka Hospital for their expert technical assistance.

\section{Funding}

No funding was received.

\section{Availability of data and materials}

The datasets used and/or analysed during the performance of this study are available from the corresponding author upon reasonable request.

\section{Authors' contributions}

YO, YA, TShi, YN, YTaki, JW, MU, TSa and SI designed the study. YO, TShi, YTanaka, JW, MU, TSa and YA analysed and interpreted the patient data. YO and YA were major contributors to writing the manuscript. YN, YTanaka, YA and SI performed the histological examination of the tumour specimens and YN and YTanaka confirmed the final histological diagnosis.

\section{Ethics approval and consent to participate}

This study was approved by the Ethics Committee of Toyooka Hospital (Toyooka, Japan; reference no. 165), and the patient's family provided written informed consent.

\section{Patient consent for publication}

The patient's family approved the publication of the case details and associated images.

\section{Competing interests}

The authors declare that they have no competing interests.

\section{References}

1. Vujanić GM, Sandstedt B, Harms D, Boccon-Gibod L and Delemarre JF: Rhabdoid tumour of the kidney: A clinicopathological study of 22 patients from the International Society of Paediatric Oncology (SIOP) nephroblastoma file. Histopathology 28: 333-340, 1996.

2. Lowe W, Weiss RM, Todd MB and True LD: Malignant rhabdoid tumor of the kidney in an adult. J Urol 143: 110-112, 1990.

3. Zhao G, Na R, Yang Y and Han R: Pure malignant rhabdoid tumor of the left kidney in an adult: A case report and review of the literature. Oncol Lett 5: 1481-1484, 2013.

4. Podduturi V, Campa-Thompson MM, Zhou XJ and Guileyardo JM: Malignant rhabdoid tumor of the kidney arising in an adult patient. Proc (Bayl Univ Med Cent) 27: 239-241, 2014.

5. Rao Q, Xia QY, Shen Q, Shi SS, Tu P, Shi QL and Zhou XJ: Coexistent loss of INI1 and BRG1 expression in a rhabdoid renal cell carcinoma (RCC): Implications for a possible role of SWI/SNF complex in the pathogenesis of RCC. Int J Clin Exp Pathol 7: 1782-1787, 2014.

6. Roberts CW, Galusha SA, McMenamin ME, Fletcher CD and Orkin SH: Haploinsufficiency of Snf5 (integrase interactor 1) predisposes to malignant rhabdoid tumors in mice. Proc Natl Acad Sci USA 97: 13796-13800, 2000.

7. Roberts CW and Biegel JA: The role of SMARCB1/INI1 in development of rhabdoid tumor. Cancer Biol Ther 8: 412-416, 2009.

8. Sigauke E, Rakheja D, Maddox DL, Hladik CL, White CL, Timmons CF and Raisanen J: Absence of expression of SMARCB1/INI1 in malignant rhabdoid tumors of the central nervous system, kidneys and soft tissue: An immunohistochemical study with implications for diagnosis. Mod Pathol 19: 717-725, 2006.

9. Hornick JL, Dal Cin P and Fletcher CD: Loss of INI1 expression is characteristic of both conventional and proximal-type epithelioid sarcoma. Am J Surg Pathol 33: 542-550, 2009.

10. Elwood H, Chaux A, Schultz L, Illei PB, Baydar DE, Billis A, Sharma R, Argani P, Epstein JI and Netto GJ: Immunohistochemical analysis of SMARCB1/INI-1 expression in collecting duct carcinoma. Urology 78: 474.e1-e5, 2011.

11. Jo VY and Fletcher CD: Epithelioid malignant peripheral nerve sheath tumor: Clinicopathologic analysis of 63 cases. Am J Surg Pathol 39: 673-682, 2015.

12. Schmidt D, Harms D and Zieger G: Malignant rhabdoid tumor of the kidney. Histopathology, ultrastructure and comments on differential diagnosis. Virchows Arch A Pathol Anat Histopathol 398: 101-108, 1982.

13. Mekhail TM, Abou-Jawde RM, Boumerhi G, Malhi S, Wood L, Elson P and Bukowski R: Validation and extension of the Memorial Sloan-Kettering prognostic factors model for survival in patients with previously untreated metastatic renal cell carcinoma. J Clin Oncol 23: 832-841, 2005.

14. Gunnarsson O, Pfanzelter NR, Cohen RB and Keefe SM: Evaluating the safety and efficacy of axitinib in the treatment of advanced renal cell carcinoma. Cancer Manag Res 7: 65-73, 2015.

15. Versteege I, Sévenet N, Lange J, Rousseau-Merck MF, Ambros P, Handgretinger R, Aurias A and Delattre O: Truncating mutations of hSNF5/INI1 in aggressive paediatric cancer. Nature 394: 203-206, 1998

16. Rousseau-Merck MF, Versteege I, Legrand I, Couturier J, Mairal A, Delattre O and Aurias A: hSNF5/INI1 inactivation is mainly associated with homozygous deletions and mitotic recombinations in rhabdoid tumors. Cancer Res 59: 3152-3156, 1999.

17. Biegel JA, Zhou JY, Rorke LB, Stenstrom C, Wainwright LM and Fogelgren B: Germ-line and acquired mutations of INI1 in atypical teratoid and rhabdoid tumors. Cancer Res 59: 74-79, 1999.

18. Pinto EM, Hamideh D, Bahrami A, Orr BA, Lin T, Pounds S, Zambetti GP, Pappo AS, Gajjar A, Agnihotri S and Broniscer A: Malignant rhabdoid tumors originating within and outside the central nervous system are clinically and molecularly heterogeneous. Acta Neuropathol 136: 315-326, 2018. 